\title{
Experimental study and theoretical analysis on impact characteristics of single pile
}

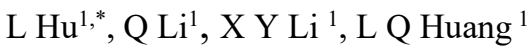 \\ ${ }^{1}$ Department of Civil Engineering, Zhejiang Ocean University, Zhoushan 316022, China
}

\begin{abstract}
The impact characteristics of a single pile are the theoretical basis of the high-strain detection technology of piles and pile driving. Firstly, a series of pile model experiments are conducted to study the characteristics of single pile penetration, axial force and friction of the pile under impact loads of different rammer loads and falling distances. Then, the dynamic model of a single pile under impact load under the condition of pile-soil slippage was established by using the elastodynamic method, and the analytical solution of the pile axial force was obtained. The results show that the theoretical solution is in good agreement with the model test results. This shows that the completely bonded model without considering slippage overestimates the frictional resistance between the pile and soil, and the pile-soil slippage model can better simulate the impact of a single pile in sand.
\end{abstract}

\section{Introduction}

The study of the characteristics of foundation piles under impact loads is the theoretical basis for techniques such as pile driving and high strain testing of foundation piles, mainly through field tests or model test methods as well as theoretical analytical methods. Most of the results of model test studies of piles focus on static load tests [1,2] or steady-state vibration tests [3], while relatively few research results of impact tests are available. Ashlock and Pak studied impact model tests of piles [4], but the scaling ratio they used was too large. To simulate the impact effect of piles, Yan Shuwang et al. established a modified static resistance model to carry out the theoretical study of the static resistance model of the soil around the pile and its application in pile driving [5], and Deeks and Randolph established an analytical model of the heavy hammer impact of pile driving [6]. The dynamic contact conditions at the pile-soil interface are an important factor affecting the theoretical simulation of foundation piles under impact loading. Most of the existing models use the pile-soil fully cohesive model. However, it has been shown that the fully cohesive model overestimates the pile-soil dynamic interaction $[7,8]$. Li Qiang by using a model with vertical presence of disturbed areas in the soil around the pile, the results of this model better reflect the pile-soil interaction during pile driving [9]. Therefore, it is important to carry out model tests and theoretical studies on the dynamic response of a single pile under impact loading for an indepth understanding of the pile-earth dynamic interaction.

In this paper, the model test method is used to study the impact characteristics of foundation piles in the saturated sandy soil foundation, and the impact theory model of foundation piles is also established to verify the reliability of the dynamic model of non-fully cohesive slip piles by solving the vibration control equations and comparing the results of the test results.

\section{Model test method}

The test model follows the corresponding rules in terms of geometry, model material, mechanical properties, loading conditions, etc, which can reflect the whole process of physical phenomena of the prototype test through the model test. The test is mainly to simulate the dynamic characteristics of a model pile of PVC pipe subjected to vertical static loading and different equal impact load excitations.

\subsection{Test instrumentation and material preparation}

\section{(1)Test equipment}

In this test, a model box is used for loading, and the box is welded with steel plates with length, width and height of $2 \mathrm{~m}, 1.5 \mathrm{~m}$ and $3 \mathrm{~m}$ respectively. The instruments for the test observation mainly include a JHBM-M miniature pressure transducer with the range of $0-200 \mathrm{~kg}$, electronic percentage meter, strain gauge, resistance strain gauge, and acceleration sensor. The installation diagram of the apparatus is shown in Figure 1(a). As seen from the schematic diagram of the impact principle shown in Figure 1(b), the system consists of two parts, one is the heavy hammer impact system and the other is the dynamic response system generated by the pile subjected to the impact load. The test uses $1.25 \mathrm{~kg}, 2.5 \mathrm{~kg}, 3.75 \mathrm{~kg}$ three kinds of hammer weight respectively in the drop distance

*Corresponding author's e-mail address :linghu821@163.com 
of $10 \mathrm{~cm}, 20 \mathrm{~cm}, 30 \mathrm{~cm}, 40 \mathrm{~cm}, 50 \mathrm{~cm}$ drop excited by the impact energy to test.

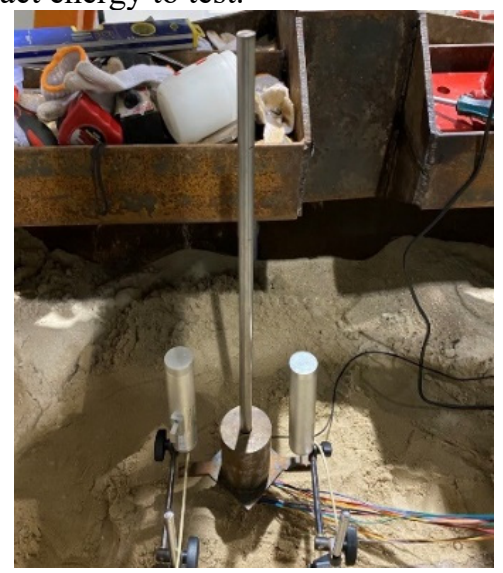

(a) Pile top impact test device

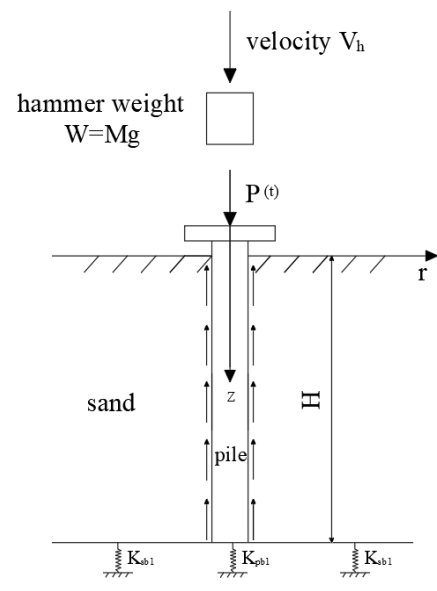

(b) Schematic diagram of impact principle
Figure 1. Impact test device

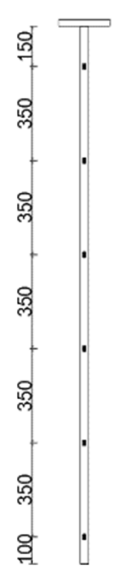

(c) Strain gauge measurement points
(2) Test materials

The sand used for the test was taken from the sea sand around Zhoushan as the foundation soil. The model box fill was roughly divided into three parts, with a $0.3 \mathrm{~m}$ thick layer of gravel composed of different grain sizes laid at the bottom as a back filter layer, and a geotextile laid on top of the back filter layer for the purpose of preventing the blockage of drainage channels by fine sand. The top layer is then filled with fine sand in layers, each $25 \mathrm{~cm}$ thick, and the soil layer is compacted. The surface of the soil layer is checked with a level to ensure its levelness during filling. The model pile is a PVC model pipe pile with a geometric similarity ratio of 30 , a pile length of 2 $\mathrm{m}$, an outer diameter of $32 \mathrm{~mm}$ and an inner diameter of $28 \mathrm{~mm}$, respectively, a modulus of elasticity $\mathrm{E}=3.75 \mathrm{GPa}$ and a Poisson's ratio $\mathrm{v}=0.39$. The strain gauges were made of $5 * 3 \mathrm{~mm}$ solderless strain gauges of BX120-5AA with a resistance of $120 \mathrm{ohm}$, and the strain gauges were pasted symmetrically with the position and spacing as shown in Figure 1(c). To prevent the wire burial from affecting the pile-soil contact conditions, the wire is threaded into the PVC pipe through the borehole, sealed with 706 silicone rubber and impermeable with insulating waterproof tape. The bottom of the pipe pile is grouted with cement mortar to close the bottom of the pile.

\subsection{Test Method.}

The impact simulation test involves applying an impact with a certain amount of energy at the top of the pile to create penetration into the pile, with the impact pulse causing strain on the pile as it travels down the pile. This in turn excites the resistance at the side and end of the pile in turn from the bottom up. Impact tests are carried out on single piles of different pile lengths to analyze the relationship between the penetration, pile shaft force and pile side frictional resistance of the model pile, and the hammer weight and drop distance of the impact load. The optimum values of hammer weight and drop distance for different pile lengths are investigated.

\section{Test results and analysis}

The results of the impact tests with three different hammer weights and three different drop distances were obtained according to the test method described above, and the variation curves of penetration, pile axial force and pile lateral frictional resistance with hammer weight and drop distance are given in Figures 2-4, respectively.

\subsection{The relationship between penetration degree and impact hammer weight and drop distance}

Figure 2 gives a comparison of the results of pile penetration, pile axial force and pile lateral frictional resistance excited by the heavy hammer when the top of the pile is subjected to $1.25 \mathrm{~kg}, 2.5 \mathrm{~kg}$ and $3.75 \mathrm{~kg}$ falling from three different drop distances $(10 \mathrm{~cm}, 30 \mathrm{~cm}$ and 50 $\mathrm{cm}$ ) at a pile length of $2 \mathrm{~m}$, respectively. As can be seen from the figure, the penetration of the pile increases with the increase of impact energy, and the penetration of the pile increases significantly at the hammer weight of $2.5 \mathrm{~kg}$ and $3.75 \mathrm{~kg}$ when the drop distance is greater than $40 \mathrm{~cm}$.

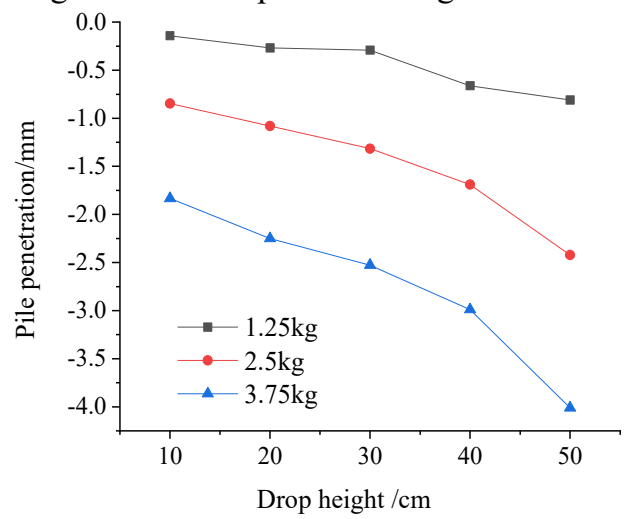

Figure 2. Variation of penetration degree with hammer weight and drop distance 


\subsection{The relationship between pile shaft force and impact hammer weight and drop distance}

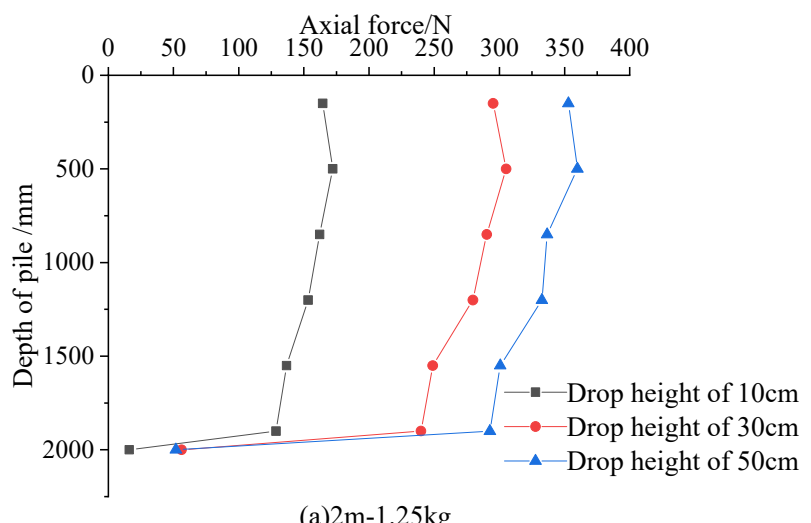

Figure 3 shows the variation curves of the pile shaft force at three different hammer weights at three drop distances along with the pile side measurement points respectively.

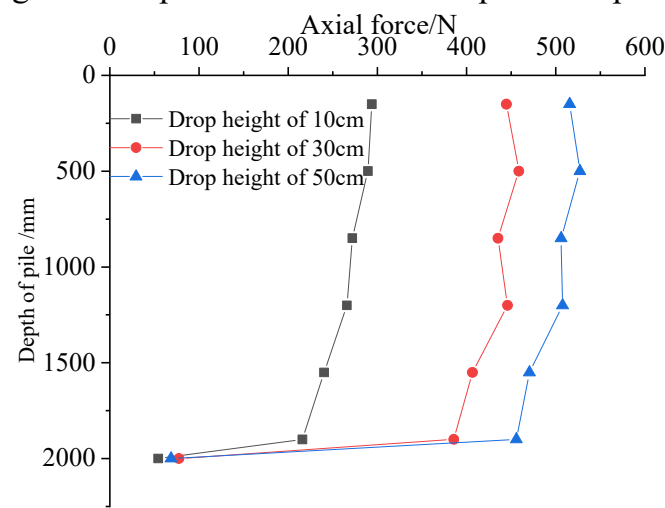

(b) $2 \mathrm{~m}-2.5 \mathrm{~kg}$

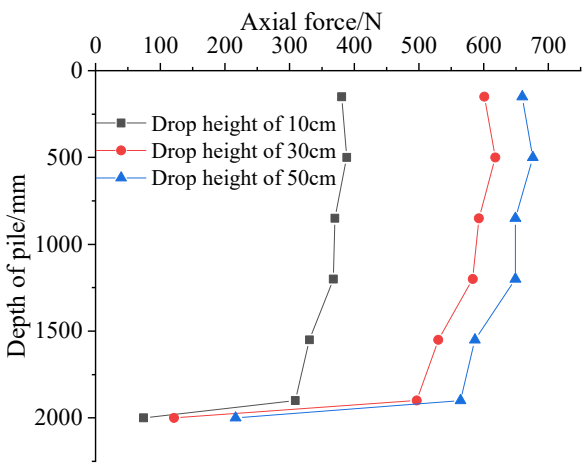

(c) $2 \mathrm{~m}-3.75 \mathrm{~kg}$

Figure 3. Variation of pile shaft force with drop distance

\subsection{The relationship between pile shaft force and impact hammer weight and drop distance}

The variation curves of the pile lateral friction resistance along the pile body for the three different hammer weights are shown in Figure 4, which is calculated from the pile shaft force. In this case, the pile lateral friction resistance is replaced by the average lateral friction resistance at the

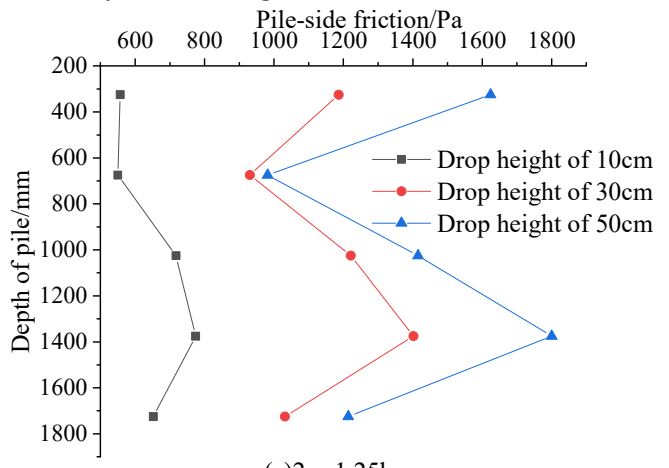

(a) $2 \mathrm{~m}-1.25 \mathrm{~kg}$ midpoint between the two measurement points. As can be seen from the figure, the heavier the hammer weight, the greater the pile-side frictional resistance excited, and the greater the drop distance at the same hammer weight, the greater the pile-side frictional resistance. The average frictional resistance of the pile side at different impact energies varies along the pile body, but all produce extreme values somewhere in the lower section of the pile, as shown in the figure around $1.4 \mathrm{~m}$.

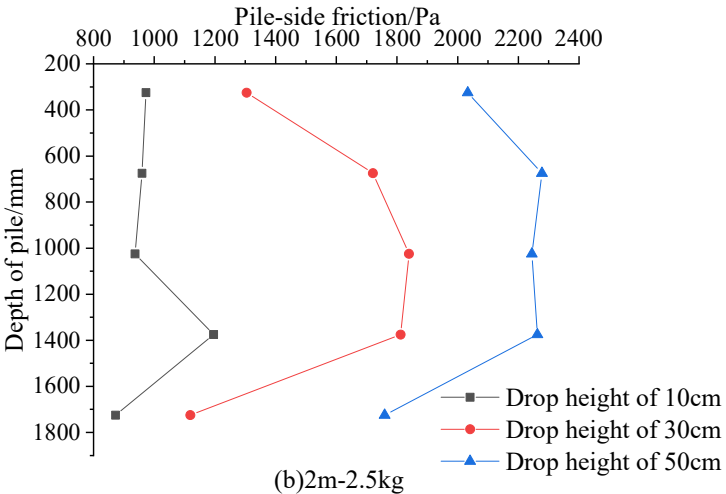




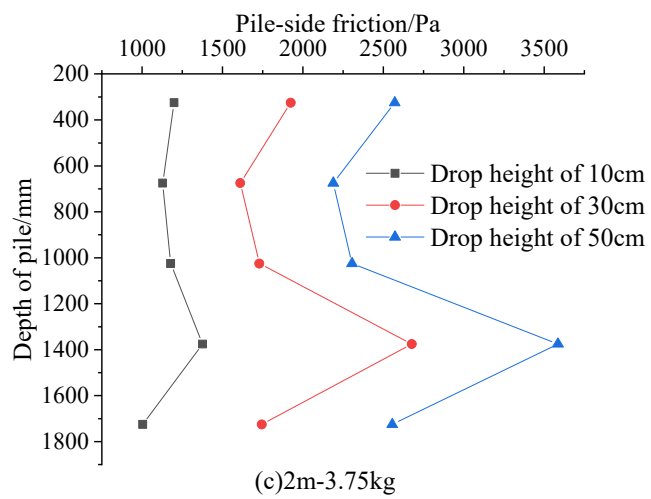

Figure 4. Relationship between pile lateral frictional resistance and drop distance

\section{Theoretical calculation model and discussion}

The controlling equation of elastic soil dynamics described in the form of displacement vector is:

$$
\bar{R} \nabla \nabla \cdot \vec{u}-\bar{\mu} \nabla \times \nabla \times \vec{u}=\bar{\rho} \frac{\partial^{2} \vec{u}}{\partial t^{2}}+\frac{\bar{A} \partial \vec{u}}{\vec{\partial} t}
$$

where $\vec{u}$ represents the displacement field vector, $\rho$ is the soil density, and $\mu$ is the shear modulus.

The pile is simplified as a one-dimensional rod, and its vibration control equation is expressed as:

$$
E_{b} \pi a^{2} \frac{d^{2} w_{b}}{d z^{2}}-f(z)=\rho_{b} \pi a^{2} \frac{d^{2} w_{b}}{d t^{2}}
$$

where $f(z)=-2 \pi a \bar{\tau}_{z r}^{(s)}(1, z)$ is the pile circumferential frictional resistance $\tau_{z r}^{(s)}$ denotes the pile lateral shear stress in the soil layer, $w_{b}$ is the pile displacement, and $a$ is the pile radius. $E_{b}$ and $\rho_{b}$ are the elastic mode and density of the pile, respectively. The boundary conditions of the soil layer are:

$\left.\bar{\sigma}_{z}^{(s)}\right|_{\bar{z}=0}=0,\left.\quad \bar{u}_{r}\right|_{\bar{r}=1}=0, E_{s}^{(a v)} \frac{\partial \bar{u}_{z}}{\partial \bar{z}}(\bar{r}, \Theta)+k_{\mathrm{sb}} \bar{u}_{z}(\bar{r}, \Theta)=0$ where $E_{S}^{(a v)}$ denotes the elastic modulus of the soil layer, and $k_{\mathrm{sb}}$ is the elastic support coefficient at the bottom of the soil layer.

The dynamic stiffness and damping at the pile-soil contact surface are simulated using springs and dampers, respectively, and the pile-soil contact condition is expressed as:

$\tau_{z r}(a, z)=-f(z) / 2 \pi a, \quad f=k_{\mathrm{f}}\left[1+\mathrm{i} D_{\mathrm{f}}(\omega)\right] \Delta w$

where $\Delta w=\left(w_{b}-u_{z}\right)$ denotes the relative pile-soil motion, $k_{\mathrm{f}}$ and $D_{\mathrm{f}}$ denote the dynamic stiffness and hysteresis damping coefficient of the pile-soil contact surface, respectively, $i=\sqrt{-1}$

The boundary conditions of the pile are:

$\left.\frac{\partial w_{b}}{\partial z}\right|_{z=0}=\frac{P(t)}{E_{b} \pi a^{2}},\left.\quad\left(E_{b} \pi a^{2} \frac{\partial w_{b}}{\partial z}+k_{p b} w_{b}\right)\right|_{z=H}=0$

where $P(t)$ is the arbitrary excitation force at the top of the pile and $k_{p b}$ is the elastic support factor at the bottom of the pile.

Referring to the solution in the literature [8], the pile axial force can be obtained. The axial force acting at any position on the pile is expressed as:

$$
\bar{p}(\bar{z})=E_{b}^{*}\left\{A_{1}\left[\kappa e^{\kappa \bar{z}}+\sum_{n=1}^{\infty} \frac{-2 \eta_{1 n} E_{n} h_{n} \sinh \left(h_{n} \bar{z}\right)}{E_{b}^{*}\left(h_{n}^{2}-\kappa^{2}\right)}\right]+B_{1}\left[-\kappa e^{-\kappa \bar{z}}+\sum_{n=1}^{\infty} \frac{-2 \eta_{1 n} F_{n} h_{n} \sinh \left(h_{n} \bar{z}\right)}{E_{b}^{*}\left(h_{n}^{2}-\kappa^{2}\right)}\right]\right\}
$$

The parameters in the formula refer to the literature[8]

When a half-sine transient force is applied at the top of the pile, the time domain response of any point of the pile can be obtained using the Fourier inversion as

$$
P_{z}(t)=\operatorname{IFT}\left[\bar{P}(i \omega) \cdot F_{\max } \omega \frac{1+e^{-\pi s / \omega}}{\omega^{2}+s^{2}}\right]
$$

where $F_{\max }$ is the peak value of the half-sine impact load, determined experimentally from the measured pulse width.
According to the above theoretical formulae, MATLAB was used to prepare a numerical calculation program to obtain the theoretical and test values of the pile shaft force at three different drop distances for a hammer weight of Comparison of theoretical and experimental values of pile axial force at three different drop distances. The calculated parameters are: pile diameter ratio 125 , soil elastic supports factor $k_{\mathrm{sb}}=1.0$, pile lateral damping factor $D_{\mathrm{f}}=0.02$, pile lateral frictional resistance factor $k_{\mathrm{f}}$ is $0.001,0.001$ and 0.0015 depending on the drop distance $100 \mathrm{~mm}, 300 \mathrm{~mm}$ and $500 \mathrm{~mm}$ respectively, and the elastic 
support factor $k_{\mathrm{pb}}$ at the bottom of the pile is 10,5 and 1 for the three different drop distances respectively. The calculation results are shown in Figure 5. It can be seen that the pile axial forces basically match for the three different drop distances, indicating that it is reasonable to use the pile-soil slippage model to simulate the impact action of pile.

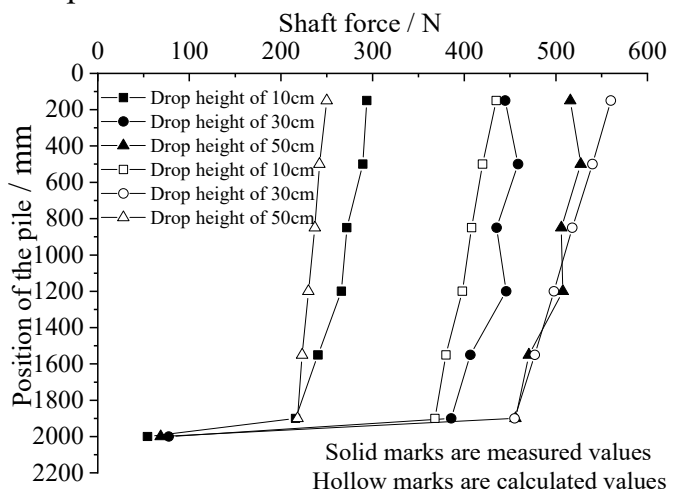

Figure 5. Comparison of theoretical calculations and actual measurements of the floating pile using slippage model

\section{Conclusion}

In this paper, the impact test of long piles in sandy soil foundations was firstly carried out by using the pile-soil impact model test device, and the variation rules of pile penetration, pile axial force and pile lateral frictional resistance were obtained for different hammer weights and different drop distances. Then the analytical solutions of pile displacement and axial force were obtained by establishing the pile-soil interaction model under the impact load considering the slip between piles and soil. The numerical calculation results show that the model can achieve a good agreement with the model test.

\section{References}

1. Wang $Y$ H, Zhang M Y and Liu X Y 2020 Experimental Study on Pile Jacking-in effects and Capacity Characteristics Based on Pile-Soil Interface J. Journal of Building Structures. 41(3):1-10.

2. Li F Y, Wang Z J, Xie X Y, Lou Y and Wang K H 2020 Model Test on Bearing Characteristic of Static Drill Rooted Energy Pile J. Rock and Soil Mechanics. 41(10):3307-3316.

3. Yu J, Shang S P, Wang H D, Lu H X and Ren H 2006 Test Research on the Steady State Excitation LargeScale Model J. Journal Of Hunan University(Natural Sciences). 33(6):11-15.

4. Ashlock J C and Pak R Y S 2009 Experimental Response of Piles in Sand under Compound Motion J Journal of Geotechnical and Geoenvironmental Engineering. 135(6), 799-808.

5. Yan S W,Chen B and Zhou R H 2003 Study on Static Resistance Model of Soil Around Pile and its Applications in Piling J. Journal Of Hydraulic Engineering.4,101-107.
6. Deeks A J and Randolph M F 1993 Analytical Modelling of Hammer Impact for Pile Driving J. Int. J. Numer. Analyt. Meth. Geomech., 17, 279-302.

7. Kim M K, Lee J S.and Kim M K 2004 Vertical Vibration Analysis of Soil-pile Interaction Systems Considering the Soil-pile Interface Behavior J. KSCE Journal of Civil Engineering. 8(2): 221-226.

8. Li Q 2007 Vertical Vibration Of Piles Embedded In Saturated Soil Considering The Imperfect Contact J. Journal Of Hydraulic Engineering. 38(3):349-354.

9. Li Q, Shi Q and Wang K H 2010 A Computational Model of Pile Vertical Vibration in Saturated Soil Based on the Radial Disturbed Zone Of Pile Driving J. 9th World Congress On Computational Mechanics And 4th Asian Pacific Congress On Computational Mechanics. IOP Conf. Ser. Mater. Sci. Eng. 10: 012069. 